\title{
O processo de conservação dos bens culturais no Brasil: reflexões do Professor Jaime Mujica
}

\section{Entrevistado}

Entrevistadora

\begin{abstract}
Prof. Jaime Mujica
Professor do Curso de Antropologia/Arqueologia da Universidade Federal de Pelotas (UFPel): Linha de Pesquisa: Conservação de Materiais Arqueológicos. Pesquisador do Laboratório Multidisciplinar de Investigação Arqueológica - LÂMINA. Professor Permanente do Mestrado em Antropologia e Arqueologia da UFPel e da Especialização em Memória, Identidade e Cultura Material (UFPel). Biólogo (Universidad de la República, Uruguay); Mestre em Botânica: Agrostología (Universidade Federal do Rio Grande do Sul); Doutor em Ciências do Solo (Universidade Federal Rural do Rio de Janeiro).
\end{abstract}

Luciana Cristina de Souza - Mestranda em História Cultural pela Universidade Estadual de Campinas e pesquisadora do Laboratório de Arqueologia Pública Paulo Duarte. Bolsista FAPESP.

E-mail: lucianasouza50@yahoo.com.br

Reconhecimento de campo, prospecção, escavação, análise e interpretação dos materiais. Essas e outras atividades são comumente citadas ao se referir à atividade do profissional formado em Arqueologia. Contudo, para que essa atividade seja possível, é necessário que o arqueólogo tenha em suas mãos os materiais preservados no intuito de que as informações ali contidas possibilitem o seu estudo. Para isso, deve-se reconhecer a importância do profissional cuja atenção se volta para a preservação e conservação desses materiais.

Para debater esse tema, a Unicamp recebeu, nos dias 22 e 23 de agosto, o pesquisador Jaime Mujica, da Universidade Federal de Pelotas - RS, que atua na área de conservação de materiais arqueológicos e ministra disciplinas na Graduação, na Especialização em Memória, Identidade e Cultura Material, e no curso de Mestrado em Antropologia e Arqueologia, todos eles na UFPel. Atua também como pesquisador associado do Laboratório Multidisciplinar de Investigações Arqueológicas (LÂMINA-UFPel), onde atualmente realiza trabalhos de escavação na Charqueada Santa Bárbara, como parte do projeto "O Pampa Negro: Arqueologia da Escravidão na Região Meridional do Rio Grande do Sul (1780-1888)".

$\mathrm{Na}$ entrevista que se segue, concedida gentilmente à Revista de Arqueologia Pública, o professor trata de vários assuntos relacionados ao seu trabalho nas charqueadas, à conservação do material arqueológico, e se propõe a analisar também a possibilidade da atividade do conservador no contexto da arqueologia de contrato. 


\section{Entrevistadora}

\section{Prof. Jaime Mujica}

Gostaria que o senhor comentasse acerca do trabalho que a equipe do LÂMINA (Laboratório Multidisciplinar de Investigação Arqueológica) realiza nas charqueadas.

O trabalho nas charqueadas teve início em agosto do ano passado, numa área que a universidade tinha intenção de comprar para transformar em prédio da Faculdade de Engenharias. Então, um colega arqueólogo, Cláudio Carle, detectou nas ruínas uma casa que corresponderia a uma estrutura de uma possível charqueada. Começamos a fazer um estudo nos arquivos, na documentação, e, realmente, nessa região aparecia uma charqueada, que se têm registros do início dos anos 1800. Fomos lá e reconhecemos o local. Há várias pessoas morando lá, uma das quais é descendente de uma das escravas que trabalhava na própria charqueada; e, outra família, descendente de portugueses, que veio trabalhar na charqueada depois da abolição da escravidão. Como a universidade pretendia fazer um prédio, realizar modificações nesse local - que depois vimos que não era exatamente nesse local que a universidade havia comprado, mas sim há uns 150 metros dali! vimos evidências do que seria uma senzala, em grande parte bem preservada. Mesmo que em uma das paredes o telhado tenha desabado, estava em muito boas condições. Pela estrutura e pelo formato percebemos que se tratava de uma senzala, pelo menos para escravos que faziam serviços domésticos. A partir daí começou todo um trabalho de avaliação da possibilidade de fazer a prospecção arqueológica para evidenciar a participação do negro africano nessa atividade produtiva, e também interpretar a localização das distintas funções da charqueada: a área dos tanques de salga, dos varais para secar o couro, do curral, da produção agrícola, do alojamento e, assim, sucessivamente. Todas estas atividades estavam enquadradas dentro de um Projeto de Pesquisa do Dr. Lúcio Menezes Ferreira intitulado: "O Pampa Negro: Arqueologia da Escravidão na Região Meridional do Rio Grande do Sul (1780-1888)", e de um projeto do qual sou o responsável chamado: "A Conservação in situ de Materiais Arqueológicos". Essa prospecção implicava na escavação e na coleta de materiais. Nesse ponto é que começava o grande problema para nós: a UFPel não tem reserva técnica. Temos o LÂMINA, fundado ano passado, com uma infraestrura precária. Deste grupo participam arqueólogos, museólogos e conservadores, e nos reunimos diversas vezes para estimar o volume de material que pode aparecer, os tipos de materiais (osso, cerêmica, etc.), o estado de conservação deles (se estão muito degradados ou menos), e, a partir dessa quantificação, começamos a elaborar protocolos de trabalho (como devem ser coletados, transportados, acondicionados e como ser tratados no laboratório). É a partir desses protocolos que fazemos as listas de insumos que serão usados para fazer a conservação, curativa ou preventiva, e para nossa grande surpresa esses produtos não estão disponíveis no mercado do Rio Grande do Sul. Então, tínhamos que reformular os protocolos de trabalho para produtos de mais fácil aquisição. A partir daí, o objetivo era encontrar algumas alternativas para que a coleta de material fosse minimizada e a destruição posterior do material também fosse minimizada. Uma alternativa que encontramos foi realizar uma etapa dos trabalhos no próprio campo, vamos supor: cacos de cerâmica muito pequenos, sem as bordas; fragmentos de vidros, que não fosse do gargalo nem da base, que não possuem valor 
diagnóstico e que não darão informações importantes serão descartados no fundo da quadrícula, no próprio local da escavação. Isso minimiza parte dos materiais e aquilo que deve ser incorporado às reservas técnicas. A segunda estratégia que utilizamos é o enterramento, que é muito discutido no Brasil, porém em diversos países essa é uma prática muito comum. Quais são as vantagens do enterramento? Parte do material que não temos condições de conservar, o material que não é importante nesse momento, ao ser enterrado no próprio ambiente da escavação, estamos propiciando a conservação do mesmo, porque o PH do solo é o mesmo, o tipo do solo é o mesmo, a variação de temperatura e umidade são mais ou menos as mesmas. Então, o objeto vai continuar tendo o mesmo equilíbrio do que antes de ser desenterrado. Adotamos essas duas metodologias: uma triagem seletiva in situ e o enterramento. Posteriormente, no laboratório é feito uma segunda triagem do material, preferencialmente com o auxílio de especialistas em materiais arqueológicos e outras tipologias, e o material que não é interessante para ele há dois caminhos: um é ser reenviado às charqueadas ou ser separado e acondicionado como coleção didática. Essas coleções didáticas (de ossos, de cerâmicas e vidros) são coleções a serem manipuladas, manuseadas e utilizadas pelos discentes o docentes vinculados ao LÂMINA.

\section{Entrevistadora}

Prof. Jaime Mujica

\section{Entrevistadora}

\section{Prof. Jaime Mujica}

\section{Quais são as perspectivas do processo de musealização após a escavação?}

Nós temos uma pessoa no grupo, a Geanine Escobar, que é afroamericana e que possui muita incidência e articulação nos movimentos negros da região. Através dela, queremos chegar até a comunidade negra, conversar com eles e perguntar se eles possuem materiais do período da escravatura, porque já sabemos que eles têm. Queremos que eles venham até o Laboratório e que nos auxiliem no reconhecimento dos materiais. Com isso, queremos criar uma ponte entre a academia e a sociedade. O que acontece em Pelotas? Acontece que muitas culturas materiais negras e indígenas estão em posse senão de colecionista, de moradores. E eles têm muito receio que a comunidade científica vá lhes tomar os materiais. Então queremos criar instrumentos para que possamos deixar esses materiais nas casas das pessoas e que os próprios atores sociais interajam com o Laboratório; uma estratégia que poderia ser implementada é que algum líder ou alguma pessoa da própria comunidade negra participe da curadoria do material. Quando tiver uma exposição, um trabalho em colégio, essas pessoas da comunidade irão reinterpretar e ressignificar essa cultura material.

Como os responsáveis pelos museus da cidade já instituídos, ou as pessoas envolvidas com esses museus e com essas instituições, percebem o Projeto Pampa Negro?

Nesse momento existe um projeto denominado Museu da Casa Oito, um museu de arqueologia em conjunto com o Museu da Tradição do Doce, em Pelotas. É uma casa dos primeiros charqueadores na praça central, onde se faria basicamente essa topografia dos registros materiais, grande parte dos materiais encontrados nas charqueadas. Mas a casa é do século XIX, então, tem que passar por uma série de reformulações técnicas para receber os materiais 


\section{Entrevistadora}

\section{Prof. Jaime Mujica}

\section{Entrevistadora}

\section{Prof. Jaime Mujica}

arqueológicos. Nesse sentido, não está muito claro o modo como vamos fazer. Este museu de arqueologia é uma parceria entre a Prefeitura Municipal e a UFPel, e está sendo coordenado pelo Dr. Pedro L. Machado Sanches, pesquisador do LÂMINA. Na cidade existem outros museus importantes, mas não existe um museu que realmente contemple as contribuições das etnias africanas e das populações originais na formação do que hoje é o Estado do Rio Grande do Sul, tirando os negros escravos e os indígenas da invisibilidade e da concepção romântica como os mesmos são tratados atualmente na sociedade.

O projeto desenvolvido no LÂMINA recebe apoio financeiro dos órgãos federais e estaduais ou do município de Pelotas?

Os apoios são muito limitados. O rol do Iphan (Instituto do Patrimônio Histórico e Artístico Nacional) se baseia nas concessões, na autorização da escavação. E nós temos boas relações com o Iphan do Rio Grande do Sul. Os órgãos de pesquisa estaduais, nesse caso, não estão contribuindo e a prefeitura também não. Basicamente são recursos do Instituto de Ciências Humanas (ICH-UFPel). Temos bolsista PET (Programa de Educação Tutorial), bolsistas de iniciação cientifica e bolsistas do Mestrado em Antropologia e Arqueologia. Mas não temos um apoio específico, o que dificulta bastante. Temos dificuldades de comprar os materiais, dificuldade para contratar outros especialistas.

Como se encontra atualmente a prática da conservação no Brasil? E se compararmos com outros países? É possível fazer um balanço?

Podemos fazer sim. Historicamente, aqui no Brasil, são poucos os institutos que trabalham com a conservação arqueológica. Os cursos de conservação e restauro no Brasil - basicamente são três - estão na maioria direcionados à curadoria de obras de arte, documentos, obras raras, tecidos, entre outros. Tirando a atuação da Dra. Yacy-Ara Froner da UFMG e da sua equipe de conservação de materiais arqueológicos, que têm uma longa trajetória nesta área, são muito escassas as referências no país. Realmente, a conservação do patrimônio arqueológico e paleontológico é pouco considerada. Esse é um primeiro problema em relação a esse tipo de curadoria. O Uruguai está no mesmo grau de avanço que o Brasil, destacando-se os trabalhos de conservação de materiais arqueológicos subaquáticos da equipe liderada pelo Dr. Antonio Lezama do Programa de Arqueologia Subacuática (PAS) da Universidad de la República . Já a Argentina, em Buenos Aires, tem um centro especializado em escavação e conservação históricas, que possui bastante experiência, o Centro de Arqueología Urbana, com conservadores reconhecidos como é o caso da Dra. Patricia Frazzi. Então, nós que nos especializamos em conservação de materiais arqueológicos, sejam eles terrestres ou subaquáticos, temos que buscar aprimoramentos técnicos fora do nosso país. Dentro da profissão de conservador, existem poucos profissionais que se direcionam para os trabalhos arqueológicos e, muito menos, para os trabalhos arqueológicos in situ, porque implica que a pessoa além de trabalhar no laboratório deve estar com vontade de trabalhar em campo. Então, se compararmos com a Espanha, por exemplo, é um país que está muito avançado na conservação de 
materiais subaquáticos, com a existência de centros equipados, além dos vários especialistas que dão cursos em distintos países. Nós, por exemplo, fizemos um curso no Uruguai com o grupo PAS de conservação de metais arqueológicos, e, depois, fizemos um curso na República Dominicana sobre a conservação do patrimônio arqueológico subaquático. Portanto, é necessário continuar com essa capacitação, fazer cursos de conservação de variadas tipologias: cursos de conservação de madeira, de artefatos ferrosos, de cerâmica, pois cada uma tem uma metodologia específica. E a grande dificuldade é porque são poucos os cursos, e muitas vezes não se têm os recursos necessários para enviar o aluno, o pesquisador, o especialista. Então, as coisas se encaminham nesse sentido. Por isso, são tão importantes as parcerias. Nós temos um vínculo bastante estreito com esse grupo uruguaio, o PAS, com um intercâmbio intenso de alunos e pesquisas conjuntas; e, agora, com o LAP (Laboratório de Arqueologia Pública - NEPAM/UNICAMP), com esse intercâmbio de professores, de alunos, que já participaram de escavação em Pelotas. Assim, vão se formando pequenos núcleos que nos complementamos na parte da conservação, até conseguirmos formar uma massa crítica significativa.

\section{Entrevistadora}

\section{Prof. Jaime Mujica}

Percebe-se que a prática de conservação demanda muitos pré-requisitos: recursos humanos, reservas técnicas, laboratórios, recursos financeiros, entre outros. Diante do atual cenário de crescimento de obras públicas de infraestutura no Brasil, e a presença de empresas de arqueologia nesse processo, como o senhor avalia a prática de escavação e conservação nesse contexto?

Você sabe que hoje mais de $90 \%$ dos projetos de prospecção e resgate arqueológicos são oriundos do que se chama de arqueologia de contrato. Somente $10 \%$ são projetos vinculados diretamente à academia. Isso implica trabalhos muito rápidos, feitos de forma muito sumária, que resultam em um volume muito grande de materiais, causando uma grave deterioração do patrimônio, porque, devido à carência de reservas técnicas no Brasil, não poderíamos retirar tantos materiais que estão preservados nos sítios arqueológicos. Essa é a primeira consideração. A segunda, é que não temos recursos humanos suficientes para fazer a curadoria desse volume de material. Desse modo, na minha visão, a questão não é melhorar a capacidade técnica dos museus, das universidades quanto à conservação curativa e preventiva. É claro que tem que melhorar, mas não é por aí. Também não é aumentar os recursos humanos especializados. 0 grande tema é minimizar o número de escavações e questionar a necessidade da retirada do material do subsolo. Há alternativas. Nós tentamos negociar com as empresas de contrato, com o proponente, para ver quais são as possibildades de não escavar no local, de o empreendimento ser descolocado para outra área com menos evidências de materiais arqueológicos. Ou seja, a ideia é minimizar a entrada desses materiais nos laboratórios. E o que acontece com grande parte dos laboratórios que não possuem condicões de conservação é que muitos materiais chegam com pouca ou nenhuma informação. Então, um material que chega descontextualizado está, a meu ver, perdido; não pode ser pesquisado, interpretado. Isso também é uma forma de perda do patrimônio, quando não sabemos de que contexto o material veio. 